\title{
Asymmetric Hypsarrhythmia: Clinical Electroencephalographic and Radiological Findings
}

\author{
Ivo Drury, Ahmad Beydoun, Elizabeth A. Garofalo, and Thomas R. Henry \\ EEG Laboratory and the Departments of Neurology and Pediatrics, University of Michigan Medical School, \\ Ann Arbor, Michigan, U.S.A.
}

\begin{abstract}
Summary: Twenty-six children ( 16 boys and 10 girls) with hypsarrhythmia and infantile spasms (IS) were studied at the University of Michigan EEG Laboratory in a 4-year period. Six ( 2 boys, 4 girls), had asymmetric hypsarrhythmia with a preponderance of both slowing and epileptiform activity over one hemisphere. All 6 had the symptomatic form of IS, 4 with dysplastic conditions, 1 with porencephaly from a cerebral infarct, and 1 with hypoxicischemic encephalopathy. Five children had focal abnormalities on either physical examination or imaging studies. Four had the highest amplitude slowing and most
\end{abstract}

epileptiform activity ipsilateral to the lesion, in 1, it was contralateral. Asymmetric hypsarrhythmia constituted $23 \%$ of cases with hypsarrhythmia examined at our EEG laboratory. The significant success in surgical therapy for some children with IS indicates the importance of identifying focal hemispheric abnormalities even if they are not apparent clinically. EEG may suggest focal changes not detected clinically or radiologically. Key Words: Asymmetric hypsarrhythmia-Infantile spasmsElectroencephalographic criteria-Cerebral dysgenesisTherapeutic implications-Neuroimaging-Children.
Since first described in 1952, hypsarrhythmia has been recognized as the classical EEG accompaniment in children with infantile spasm (IS). Although the pattern of high-voltage asynchronous slowing and multifocal independent spikes is the prototypic pattern, there has been increasing recognition of the variability in EEG pattern with time and in different behavioral states. Of the five major variants described by Hrachovy et al. (1984), one, the asymmetric variant, occurred most commonly in patients with cystic lesions of one hemisphere with an amplitude reduction over the side of the cyst. We report the clinical, EEG, and radiologic findings in 6 patients with the asymmetric variant, identified through retrospective review of all hypsarrhythmia EEGs examined in a consecutive 48-month period at the University of Michigan EEG Laboratory.

\section{MATERIALS AND METHODS}

Since 1986, all EEG recordings performed at the University of Michigan have had their diagnoses entered into a computerized database by an alpha-

Received February 1994; revision accepted March 1994.

Address correspondence and reprint requests to Dr. I. Drury at EEG Laboratory, University Hospital 1B300/0036, 1500 E. Medical Center Dr., Ann Arbor, MI 48109-0036, U.S.A. numeric system: 76 EEGs from 26 patients (range one to six), with one or more EEG diagnoses of hypsarrhythmia in a 4-year period were identified; in each case, review of the recording confirmed the original diagnosis. Each EEG recording was performed on 21-channel Nihon Kohden instruments according to the International 10-20 system of electrode placement. Recording duration was $30-45$ min. Sleep recording was obtained in most EEGs, and intermittent photic stimulation (IPS) was performed routinely. EEGs were classified as asymmetric hypsarrhythmia when at least half of the record showed that one hemisphere had both $\geqslant 50 \%$ occurrence of epileptiform activity and $\geqslant 50 \%$ amplitude of delta frequency activity as compared with the other hemisphere.

Medical record review determined age of seizure onset; details of birth history; findings on initial and follow-up physical examinations, results of diagnostic studies, including brain imaging, chromosome studies, metabolic screens, blood counts, and chemistries; the presumed etiology of the IS; treatment used; and response to treatment. Imaging studies were performed in 23 of the 26 patients, and the best available computed tomography (CT) or magnetic resonance imaging (MRI) scan was reviewed to ensure accuracy of the original radiologic 
diagnosis. Two other patients had ultrasound examinations.

\section{RESULTS}

Six of the 26 children showed asymmetric hypsarrhythmia on one or more (range one to four) EEG recordings. The clinical, EEG, and radiologic findings in these 6 patients are summarized in Table 1. There were 16 boys and 10 girls in the group as a whole, but 4 of the 6 children with asymmetric hypsarrhythmia were girls. Five children had IS onset before age 2 months; 3 of these were in the asymmetric group. Neither of these differences reached statistical significance.

Table 2 shows the relation between the presence of focal clinical or radiologic findings and asymmetric hypsarrhythmia. There was a statistically significant correlation between presence of focal findings

TABLE 1. Clinical, EEG, and radiologic findings in asymmetric hypsarrhythmia

\begin{tabular}{|c|c|c|c|c|c|c|c|c|}
\hline $\begin{array}{c}\text { Patient/ } \\
\text { sex/age } \\
\text { at } \\
\text { seizure } \\
\text { onset } \\
\text { (mo) }\end{array}$ & $\begin{array}{c}\text { Physical } \\
\text { examination }\end{array}$ & $\begin{array}{l}\text { No. of } \\
\text { EEG } \\
\text { studies }\end{array}$ & Waking EEG & Sleep EEG & Ictal EEG & Imaging & Etiology & $\begin{array}{l}\text { Response } \\
\text { to therapy }\end{array}$ \\
\hline $1 / \mathrm{F} / 2$ & $\begin{array}{l}\text { L hemiparesis, } \\
\text { hypotonic NL } \\
\text { retina }\end{array}$ & 3 & $\begin{array}{l}\text { Normal L } \\
\text { hemisphere, } \\
\text { slowing } \\
\text { disorganization } \\
\text { but few spikes } \\
\text { R hemisphere }\end{array}$ & $\begin{array}{l}\text { Normal L } \\
\text { hemisphere; } \\
100-150 \mu \mathrm{V} \\
\text { slowing R. } \\
\text { hemisphere } \\
\text { with multiple } \\
\text { spike foci }\end{array}$ & $\begin{array}{l}\mathbf{R} \text { hemisphere } \\
\text { polyspikes } \\
\text { followed by } \\
\text { decrement }\end{array}$ & $\begin{array}{l}\text { Partial agenesis } \\
\text { corpus } \\
\text { callosum }\end{array}$ & $\begin{array}{l}\text { ? Aicardi's } \\
\text { syndrome }\end{array}$ & No follow-up \\
\hline 2/M/6 & $\mathbf{R}$ hemiparesis & 4 & $\begin{array}{l}400 \mu \mathrm{V} \text { slowing } \\
\text { with multiple } \\
\text { spikes L } \\
\text { hemisphere; } \\
\text { few bursts of } \\
\text { slowing and } \\
\text { infrequent } \\
\text { occipital spikes } \\
\mathrm{R} \text { hemisphere }\end{array}$ & $\begin{array}{l}\text { Continued } \\
\text { marked } \\
\text { asymmetry; } \\
\text { sleep spindles } \\
\text { only on } \mathrm{R}\end{array}$ & $\begin{array}{l}\text { Diffuse } \\
\text { high-amplitude } \\
\text { slow wave with } \\
\text { superimposed } \\
\text { fast wave } \\
\text { followed by } \\
\text { decrement }\end{array}$ & $\begin{array}{l}\text { Hypodense lesion } \\
\text { L hemisphere } \\
\text { consistent with } \\
\text { proximal MCA } \\
\text { occlusion }\end{array}$ & Infarct & Improvement \\
\hline $3 / \mathrm{F} / 6$ & $\begin{array}{l}\text { Blind, hypotonic, } \\
\text { quadriparesis, } \\
\text { profound delay }\end{array}$ & 1 & $\begin{array}{l}300 \mu V \text { slowing } \\
\text { with multiple } \\
\text { spikes } \mathrm{R} \\
\text { hemisphere; } \\
\text { rare } \\
\text { independent } \mathrm{L} \\
\text { occipital spikes }\end{array}$ & None obtained & $\begin{array}{l}\text { Generalized } \\
\text { polyspike- } \\
\text { and-wave; } \mathbf{R} \\
\text { hemisphere } \\
\text { spike-and-wave }\end{array}$ & Hydrocephalus & $\begin{array}{l}\text { Preterm: } \\
\text { GA 28W } \\
\text { Gr. IV IVH }\end{array}$ & No follow-up \\
\hline $4 / \mathrm{M} / 5$ & $\begin{array}{l}\text { Microcephaly, } \\
\text { profound delay, } \\
\text { quadriparesis R } \\
>\text { L }\end{array}$ & 1 & None obtained & $\begin{array}{l}\text { Marked voltage } \\
\text { suppression } L \\
\text { hemisphere; } \\
\text { infrequent } \\
\text { spikes, no } \\
\text { spindles; } 400 \\
\mu V \text { slowing } R \\
\text { hemisphere, } \\
\text { with multiple } \\
\text { spike foci but } \\
\text { preserved } \\
\text { spindles }\end{array}$ & None & $\begin{array}{l}\text { Multiple left } \\
\text { hemisphere } \\
\text { cysts, some } \\
\text { with soft tissue } \\
\text { mural nodules; } \\
\text { marked } \\
\text { enlargement L } \\
\text { lateral } \\
\text { ventricle; } \\
\text { multiple areas } \\
\text { of white matter } \\
\text { T2 increase; } R \\
\text { posterior } \\
\text { arachnoid cyst }\end{array}$ & $\begin{array}{c}\text { Intrauterine } \\
\text { infection }\end{array}$ & $\begin{array}{l}\text { No } \\
\text { improvement }\end{array}$ \\
\hline $5 / F / 2$ & $\begin{array}{l}\text { Marked delay, } \\
\text { spastic } \\
\text { quadriparesis, } \\
\text { microphthalmia } \\
\text { OS, choroid, } \\
\text { coloboma OD }\end{array}$ & 2 & $\begin{array}{l}\text { Moderately } \\
\text { asychronous } \\
200 \mu \mathrm{V} \\
\text { slowing, } \\
\text { maximum } \mathrm{L} \\
\text { hemisphere } \\
\text { multiple spike } \\
\text { foci, maximum } \\
\mathrm{L} \text { hemisphere }\end{array}$ & $\begin{array}{l}\text { Increased slowing } \\
\text { asynchrony, } \\
\text { and epileptic } \\
\text { activity }\end{array}$ & None & $\begin{array}{l}\text { Partial agenesis } \\
\text { corpus } \\
\text { callosum; } \\
\text { intraconal } \\
\text { retrobulbar } \\
\text { mass OS; cyst } \\
\text { posterior to } \\
\text { third ventricle } \\
\text { and to left of } \\
\text { midline }\end{array}$ & $\begin{array}{l}\text { Aicardi's } \\
\text { syndrome }\end{array}$ & Improvement \\
\hline $6 / F / 2$ & $\begin{array}{l}\text { Irritable } \\
\text { hypotonic }\end{array}$ & 3 & $\begin{array}{l}200 \mu \mathrm{V} \text { slowing } \\
\text { and multiple } \\
\text { foci } \mathrm{L} \\
\text { hemisphere; } \mathrm{R} \\
\text { hemisphere } \\
\text { infrequent } \\
\text { independent } \\
\text { slowing and } \\
\text { spikes }\end{array}$ & $\begin{array}{l}\text { Greater } \\
\text { symmetry and } \\
\text { synchrony; } \\
\text { sparse spindles } \\
\mathbf{R}=\mathrm{L}\end{array}$ & None & $\begin{array}{l}\text { Dysmorphic L } \\
\text { temporal lobe } \\
\text { with } \\
\text { inferioschizence } \\
\text { cleft; vascular } \\
\text { malformation L } \\
\text { thalamus }\end{array}$ & Dysgenesis & Improvement \\
\hline
\end{tabular}

MCA, middle cerebral artery; Gr, grade; GA, gestational age. 
TABLE 2. Relation between focal clinical or radiologic findings and asymmetric hypsarrhythmia

\begin{tabular}{lcc}
\hline Parameter & Nonfocal & Focal \\
\hline Symmetric & 16 & 4 \\
Asymmetric & 1 & 5 \\
Total & 17 & 9 \\
\hline
\end{tabular}

$\mathrm{p}=0.01$.

and EEG asymmetry ( $\mathrm{p}=0.01$, Fisher's test). Of the 5 patients with asymmetric EEGs and asymmetric physical examinations or imaging studies, both the higher amplitude slowing and predominance of epileptiform activity was ipsilateral to the lesion in 4 patients; in 1 patient (patient 4 ), the hypsarrhythmia pattern was markedly attenuated on the side where brain tissue was replaced by multiloculated cysts (Figure 1A and B). Patient 3, who was born at a gestational age of 28 weeks and had a grade IV intraventricular hemorrhage had striking asymmetry on EEG but no focal findings on physical examination or CT studies.

Four of the 20 patients with symmetric hypsarrhythmia had focal physical or radiologic findings. Three had cystic lesions (two were ischemic and the third had a probable developmental anomaly, with the cyst associated with deformity and hypoplasia of the ipsilateral cerebral hemisphere). Two of the 3 had contralateral corticospinal tract findings, the third had a nonfocal neurological examination. The fourth patient had agenesis of corpus callosum as part of Aicardi's syndrome but no unilateral hemisphere lesions.

Various etiologic factors were responsible for de-
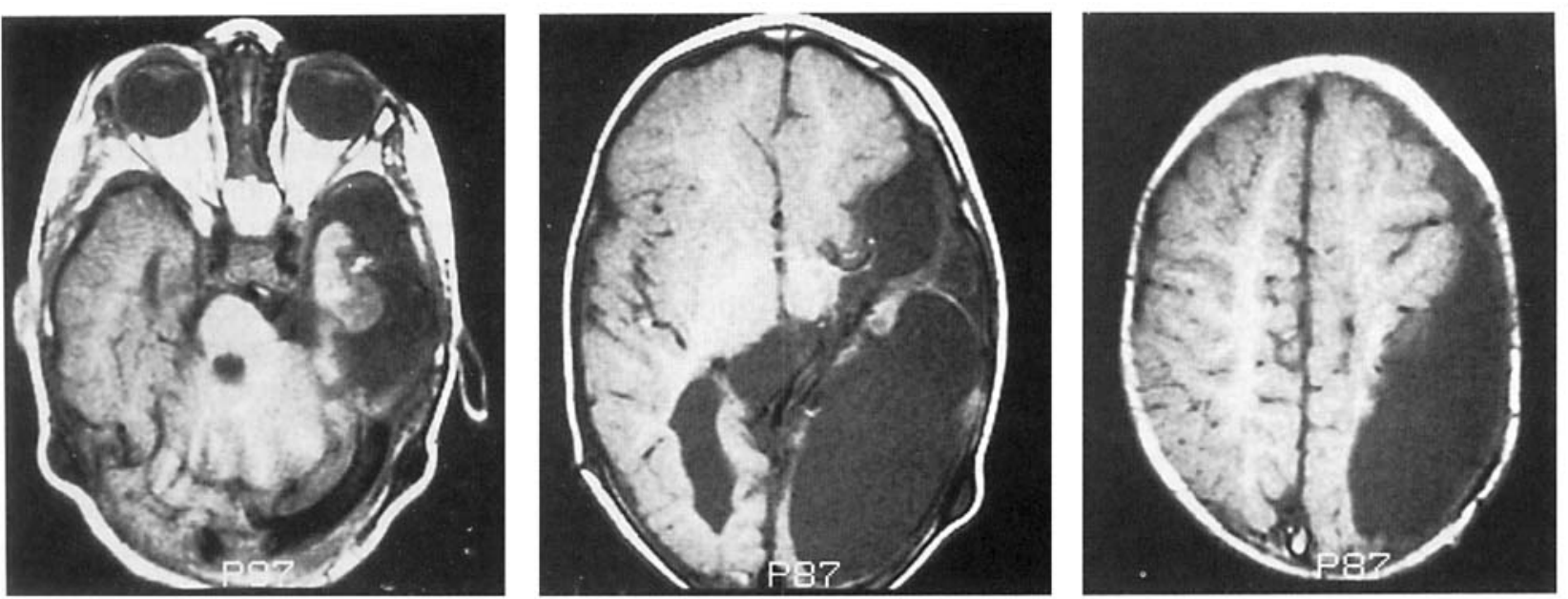

$1 \mathrm{~A}$

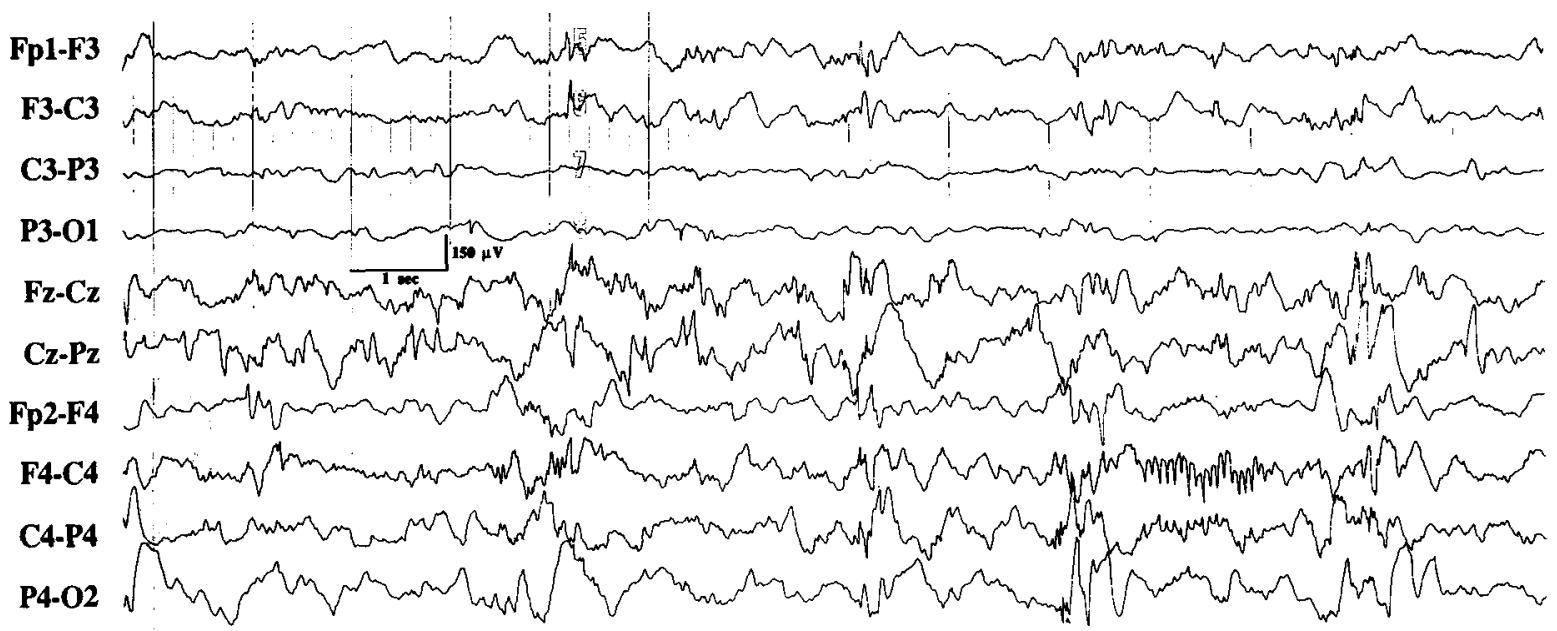

FIG. 1. A: Patient 4. Magnetic resonance images show multiple cysts in left hemisphere associated with soft tissue mural nodules. The most inferior of these $T_{1}$-weighted axial images (left) also demonstrates a soft tissue mass posterior to the pons and an inhomogeneous left middle fossa mass, both of which may represent dysplasia. A probably arachnoid cyst is visible at midline in middle image. Images were produced with a 1.5-T GE Signa system with spin-echo sequences (TE $=20 \mathrm{~ms}$, TR = 600 ms). B: EEG sample recorded in stage II sleep at age 5 months. Right hemisphere displays a typical hypsarrhythmic pattern but with well-preserved sleep spindles. Over the cystic left hemisphere, there was marked voltage attenuation and complete absence of sleep spindles. 
velopment of IS in children with symmetric hypsarrhythmia (Table 3). All 3 patients with the cryptogenic form were in the symmetric group. In contrast, most asymmetric cases were children with developmental anomalies of the nervous system. Two patients of all 26 patients in the study group had definite Aicardi's syndrome, 1 was in the symmetric and 1 was in the asymmetric group. One other (patient 1) was first noted to have IS at age 2 months. She showed unilateral hypsarrhythmia on the right side, associated with mild left hemiparesis. An imaging study showed partial agenesis of corpus callosum, but she did not have the retinal or vertebral body abnormalities of Aicardi's syndrome. The other 2 children with dysplastic syndromes and asymmetric hypsarrhythmia had no specific syndrome recognized. The mother of patient 4 had an intrauterine infection at a gestational age of 5 months, and the child was born with multiple intraventricular hemorrhages and cystic lesions with very little normal brain tissue in the left hemisphere (Figure 1A and B). Patient 6 had multiple congenital anomalies, including left temporal dysmorphism with gyral thickening and an inferior schizencephalic cleft and enhancing linear structures in left thalamus consistent with vascular malformation (Fig. $2 \mathrm{~A}$ and $\mathrm{B}$ ). Of the 2 patients with asymmetric hypsarrhythmia who did not have dysplastic conditions, 1 (patient 2) also had a focal lesion due to perinatal proximal middle cerebral artery occlusion. Another patient (patient 3) born at a gestational age of 28 weeks, had multiple intraventricular hemorrhages and hydrocephalus. In the 4 patients with asymmetric hypsarrhythmia who had more than one EEG recording performed, the asymmetric features were consistently present, occupying $50-85 \%$ of any individual tracing.

Ictal events occurred in three EEGs of 3 patients. In 1 , with left hemisphere porencephaly (patient 2 ), a single seizure consisting of repetitive clonic activity of both feet was accompanied by a diffuse highamplitude slow wave with superimposed lowamplitude fast activity followed by a generalized voltage decrement. Two other patients had lateral-

TABLE 3. Etiologic factors in patients with symmetric and asymmetric hypsarrhythmia

\begin{tabular}{lcc}
\hline \multicolumn{1}{c}{ Etiology } & Symmetric & Asymmetric \\
\hline Cryptogenic & 3 & 0 \\
Developmental anomalies & 1 & 4 \\
Chromosomal & 6 & 0 \\
Intraventricular hemorrhage & 3 & 1 \\
Hypoxic-ischemic encephalopathy & 5 & 0 \\
Focal ischemic & 1 & 1 \\
Infectious & 1 & 0 \\
\hline
\end{tabular}

ized seizure discharges. The asymmetric IS of the child with possible Aicardi's syndrome (patient 1) were accompanied by high-frequency polyspike discharges over the right hemisphere with a parasagittal emphasis followed by a voltage decrement. The EEG study in patient 3 showed generalized myoclonic jerks associated with generalized highamplitude polyspike-and-wave discharge with no electrodecremental response and a partial seizure in which the child rolled both eyes back and appeared unresponsive; this was accompanied on EEG by high-amplitude spike-and-wave activity widely distributed over the right hemisphere (Fig. 3). None of her IS were captured on a single EEG.

The response to therapeutic interventions and adequate follow-up was known in 15 patients. There was no statistically significant difference in outcome between the symmetric and asymmetric groups.

\section{DISCUSSION}

The syndrome of IS first reported by West in 1841 has hypsarrhythmia as its classic EEG accompaniment, as described by Gibbs and Gibbs (1952). From the outset, Gibbs and Gibbs (1952) recognized not only the variability in EEG appearance with time and location but at least one of the more sustained specific variants of the prototypic pattern, i.e., primarily high-voltage bilaterally asynchronous slow activity. Hrachovy et al. (1984) described five major variations of hypsarrhythmia documented from 290, 24-h polygraphic recordings in 67 patients with IS. They justified considering these variants under the rubric hypsarrhythmia because the EEGs retained some of the characteristics of the original pattern and were associated with the same seizure types. Hrachovy et al. (1984) described the asymmetric variant as one in which there was consistent voltage asymmetry between the two sides, varying from a regional asymmetry to a purely unilateral pattern. They did not specify (nor have other investigators) the degree of asymmetry that had to exist for this classification to be applied, but indicated that asymmetric hypsarrhythmia was most commonly observed in the setting of a large cystic defect in one hemisphere. They illustrated this with an example with significant voltage attenuation ipsilateral to a porencephalic cyst. It is unfortunate that Hrachovy et al. (1984), did not indicate how common these variants were in the 67 patients, how consistent the findings were in serial EEGs from the same patient, or how close the correlation was between the presence of a focal hemispheric lesion, cystic or otherwise, and the appearance of an asymmetric hypsarrhythmia pattern. 

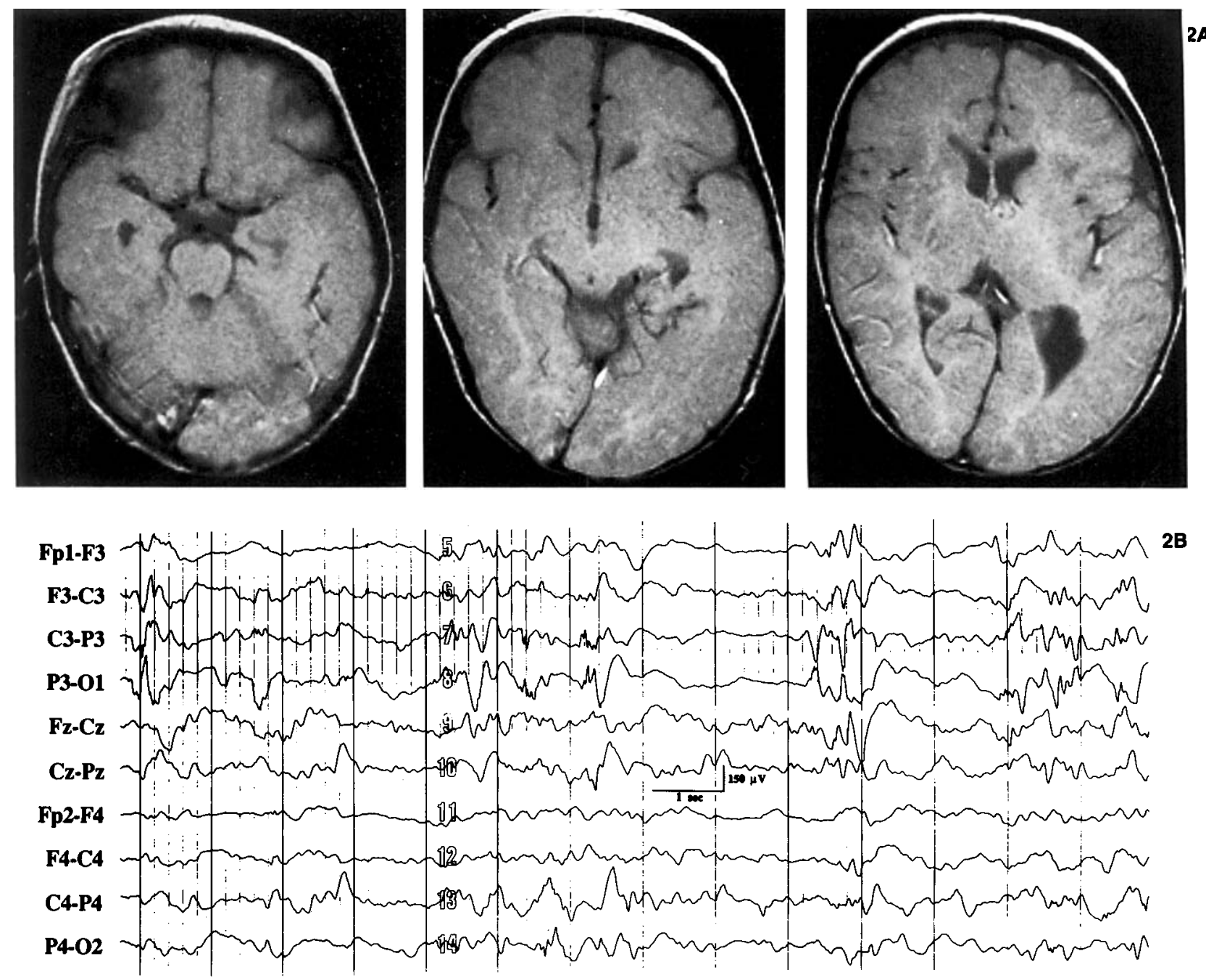

FIG. 2. A: Patient 6. Magnetic resonance images show severe dysplasia of left temporoparietal cortex associated with a schizencephalic cleft extending from inferotemporal surface to lateral ventricle [apparent as irregular linear cerebrospinal fluid (CSF) intensities in the temporal lobe substance on the most inferior and middle of these axial images]. The most superior image (right) also demonstrates a small area of curvilinear CSF intensities in left anterior thalamus adjacent to the anterior horn of the lateral ventricle; this area demonstrated marked gadolinium enhancement and is most consistent with a small vascular malformation. These proton-density images were produced with a 1.5-T GE Signa system with spin-echo sequences (TE = $30 \mathrm{~ms}$, TR $=3,000 \mathrm{~ms}$ ); subject left is displayed on image right. B: EEG sample recorded in wakefulness at age 3 months. Focal epileptiform activity and asynchronous delta is concentrated over the left hemisphere.

In this small series, collected retrospectively and with only standard EEG recording lengths, 6 of 26 patients showed an asymmetric hypsarrhythmia pattern in at least one EEG. In contrast to Hrachovy et al. (1984), we noted that the asymmetric hypsarrhythmia pattern, when associated with focal lesions, was most prominent ipsilateral to the lesion in 4 of the 5. Our findings are consistent with those of Cusmai et al. (1993), who described 32 patients with symptomatic IS caused by perinatal insults. In 15 patients with porencephalic lesions, the EEG showed asymmetric hypsarrhythmia with highamplitude slowing and epileptiform activity ipsilateral to the lesion.
Opinions conflict regarding whether IS represent a disorder of primarily cerebral hemisphere or brainstem origin. Much evidence has indicated a primary disturbance in the pons, including autopsy findings (Satoh et al., 1986), fluorodeoxyglucose positron emission tomography (PET) (Chugani et al. 1992), abnormal brainstem auditory evoked potentials (Kaga et al., 1982), disturbed REM sleep (Hrachovy et al., 1991), and defects in neurotransmitter metabolism (Silverstein and Johnston, 1984). Hrachovy's observations (1984) of decreased amplitude in the hypsarrhythmic pattern ipsilateral to a cystic lesion in one hemisphere would also be quite consistent with a subcortical disturbance. 


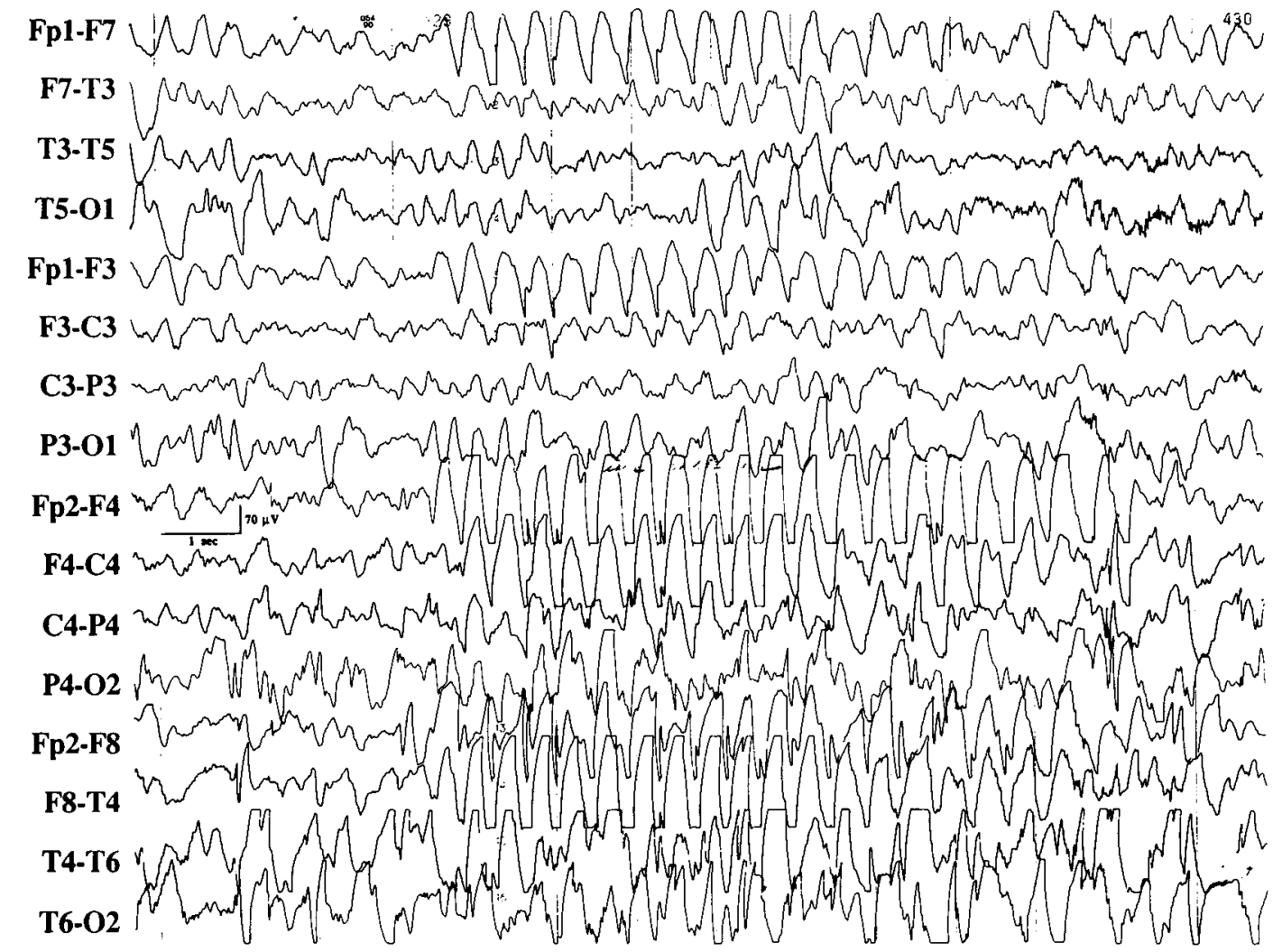

FIG. 3. Patient 3. Recorded partial seizure associated with the child rolling both her eyes back and appearing unresponsive. Its EEG accompaniment was high-amplitude spike-and-wave activity widely distributed over the right hemisphere (reprinted from Drury and Henry, Ictal patterns in generalized epilepsy. $J$ Clin Neurophysiol 1993;10:268-80, with permission).

However, many recently acquired pieces of data favor a primarily cortical origin for at least some patients with this disorder with secondary involvement of the brainstem. Isolated cases of resolution of IS with surgical resections from the cerebral hemispheres (Branch and Dyken, 1979; Mimaki et al., 1983; Palm et al., 1988; Uthman et al., 1991) and of patients with series of IS triggered by partial seizures (Carazana et al., 1990; Donat and Wright, 1991) have been reported. The autopsy series of Jellinger (1987) indicates that most neuropathologic changes in children dying of IS are in the cerebral hemispheres. Chiron et al. (1993) documented disturbances of blood flow to portions of the cerebral hemisphere. The finding of Jambaqué et al. (1993) of visuospatial deficits documented with neuropsychological testing, was supported by single photon emission CT scans showing perfusion defects in the parieto-occipital region in 3 patients with IS. Subtle disturbances of cortical function were also detected with PET, when CT and MRI scans had been negative (Chugani et al. 1990, 1992, 1993). The PET findings in the cerebral hemispheres correlated well with localized abnormalities on EEG and findings of focal cortical dysplasia in the resected surgical specimens; moreover, this was associated with a favorable response in these patients to surgical therapy.

Overall, the outlook remains poor for children with IS in general and for the symptomatic group in particular (Bobele and Bodensteiner, 1990). The occurrence of asymmetric hypsarrhythmia with welldefined unilateral developmental anomalies of the cerebral hemispheres is well recognized (Tjiam et al., 1978, Vigevano et al., 1989). The report of Vigevano et al. (1989) documented the potential value of surgical resection in such children. Recently, attention has been paid to the presence of the much more subtle developmental anomalies in children with intractable IS and later forms of symptomatic generalized epilepsy (Chugani et al. 1990, 1993; Vinters et al., 1993). Almost all these children have shown asymmetries of EEG background and interictal epileptiform activity. Our observations in this series of patients indicate the importance of identifying children who have asymmetric features in their hypsarrhythmia pattern; EEG may detect changes not identified by either physical examination or imaging studies, and the data of Chugani et al. $(1990,1992,1993)$ indicate that these children 
may profit from functional imaging studies such as PET and consideration of surgical therapy.

\section{REFERENCES}

Bobele GB, Bodensteiner JB. Infantile spasms. Neurol Clin 1990;8:623-45.

Branch CE, Dyken PR. Choroid plexus papilloma and infantile spasms. Ann Neurol 1979:5:302-4.

Chiron C, Dulac O, Bulteau C, et al. Study of regional cerebral blood flow in West syndrome. Epilepsia 1993;34:707-15.

Chugani HT, Shewmon DA, Shields WD, et al. Surgery for intractable infantile spasms: neuroimaging perspectives. Epilepsia 1993;34:764-71.

Chugani HT, Shields DW, Shewmon DA, Olson DM, Phelps ME, Peacock WJ. Infantile spasms: I. PET identifies focal cortical dysgenesis in cryptogenic cases for surgical treatment. Ann Neurol 1990;27:406-13.

Chugani HT, Shewmon DA, Sankar R, Chen BC, Phelps ME, Infantile spasms. II. Lenticular nuclei and brainstem activation on positron emission tomography. Ann Neurol 1992;31: 212-9.

Cusmai R, Ricci S, Pinard JM, Plouin P, Fariello G, Dulac O. West syndrome due to perinatal insults. Epilepsia 1993;34: $738-42$.

Donat JF, Wright FS. Simultaneous infantile spasms and partial seizures. J Child Neurol 1991;6:246-50.

Gibbs FA, Gibbs EL. Atlas of electroencephalography, vol. 2. Reading, MA: Addison-Wesley 1952.

Hrachovy RA, Frost JD Jr., Kellaway P. Hypsarrhythmia: variations on the theme. Epilepsia 1984;25:317-25.

Hrachovy RA, Frost JD, Kellaway P. Sleep characteristics in infantile spasms. Neurology 1981;31:688-94.

Jambaqué I, Chiron C, Dulac O, Raunaud C, Syrota P. Visual inattention in West syndrome: neuropsychological and neurofunctional imaging study. Epilepsia 1993;34:692-700.

Jellinger K. Neuropathological aspects of infantile spasms. Brain Dev 1987;9:349-57.

Kaga K, Marsh RR, Fukuyama Y. Auditory brainstem responses in infantile spasms. Int J Pediatr Otorhinolaryngol 1982;4:5767.

Mimaki T, Ono J, Yabuuchi H. Temporal lobe astrocytoma with infantile spasms. Ann Neurol 1983;14:695-6.

Palm DG, Brandt M, Korinthenberg R. West syndrome and Lennox-Gastaut syndrome in children with porencephalic systs: long term follow-up after neurosurgical treatment. In: Niedermyer $\mathrm{E}$, Degen $\mathrm{R}$, eds. The Lennox-Gastaut syndrome, New York: Alan R. Liss, 1988:419-26.

Satoh J, Mizutani T, Morimatsu Y. Neuropathology of the brainstem in age-dependent epileptic encephalopathy-especially of cases with infantile spasms. Brain Dev 1986;8:443-9.

Silverstein F, Johnston MV. Cerebrospinal fluid monoamine metabolites in patients with infantile spasms. Neurology 1984; 34:102-5.

Tijam AT, Stefanko S, Schenk VWD, de Vlieger M. Infantile spasms associated with hemihypsarrhythmia and hemimegalencephaly. Dev Med Child Neurol 1978;20:779-89.

Uthman BM, Reid SA, Wilder BJ, Andriola MR, Beydoun AA. Outcome for West syndrome following surgical treatment. A case report. Epilepsia 1991;32:668-71.

Vigevano F, Bertini E, Boldrini R, et al. Hemimegalencephaly and intractable epilepsy: benefits of hemispherectomy. Epilepsia 1989;30:833-43.

Vinters HV, De Rosa MJ, Farrell MA. Neuropathologic study of resected cerebral tissue from patients with infantile spasms. Epilepsia 1993;34:772-9.

West WJ. On a peculiar form of infantile convulsions. Lancet $1841 ; 1: 724-5$. 